\title{
Sticks and Stones
}

Changing Name of Epilepsy in Korea; Cerebroelectric Disorder (noi-jeon-jeung, 뇌전증,): My Epilepsy Story. Kim HD, Kang HC, Lee SA, Huh K, Lee BI. Epilepsia 2014;55:384-386.

Public misconception of epilepsy may lead to significant stigma to the disease itself, thereby causing impaired quality of life in people with epilepsy. Traditionally, epilepsy has been considered to be the consequence of evanescent spiritual forces, and even demonic possession (in many countries). The names of epilepsy in some East Asian countries originated from China, and include madness in their meaning. We recently changed the Korean name of epilepsy, gan-jil (간질: a crazy, convulsive disease having meaning similar to), to a neutral and scientifically explainable name: noi-jeonjeung (뇌전증; cerebroelectric disorder). We expect that changing the stigmatized name of epilepsy to a neutral and scientific term with the meaning of cerebroelectric disorder will reduce the social stigma by understanding of epilepsy as one of the neurologic disorders.

\section{Commentary}

Sticks and stones may break my bones but words will never harm me. It's interesting that such an innocent nursery rhyme can completely get it so wrong. In the field of medicine certain words can be much more damaging than the condition itself. Sadly, epilepsy is a prime example. Most epileptologists and neurologists often observe that when they diagnose someone with new onset epilepsy by how that individual and their family is left feeling uncomfortable every time the word "epilepsy" is uttered. Many patients prefer to describe their condition as a seizure disorder rather than be labeled as epileptic (1). Therefore, it is of particular interest that in the January 2014 issue of the journal Epilepsia Kim and colleagues (2), representing a number of institutions in the Republic of Korea, report their story of changing the name of epilepsy in Korea.

Kim and colleagues (2) recount a fairly detailed process beginning in the year 2007 and culminating with the publication of their paper of the difficulty and struggle to get the word changed. For years, the Korean language represented epilepsy and seizures with characters connoting psychiatric conditions roughly translating to madness, or associated with animal diseases, such as mad pig disease. The Korean term for epilepsy represented temporary demonic possession (2). Korean neurologists appropriately noted that this particular choice of word does not reflect the modern scientific understanding of epilepsy as we know it, and more importantly suffocates the afflicted and their families with a toxic stigma. Thus, the Korean name of epilepsy was changed to a more neutral term that conveys a cerebroelectric disorder.

Epilepsy Currents, Vol. 14, No. 5 (September/October) 2014 pp. 257-258 (c) American Epilepsy Society

OPEN $\odot$ ACCESS Freely available online
In the United States, tagging someone with epilepsy can effectively shun the person by setting up legal barriers to employment, education, driving, insurance, and sports. Major public health organizations like the U.S. Centers for Disease Control and Prevention recognize stigma as a major public health issue (3). The stigma of using the word "epilepsy" was addressed by the Institute of Medicine (IOM) report on the public health dimensions of epilepsy by noting the confusing nature of epilepsy-related terminology. Historically, in the United States, terms to describe the disorder have included the sacred disease, or falling sickness (1). More recently, terms such as fits and spells have been used to describe epileptic seizures. The problem is that epilepsy is actually a spectrum of disorders that can range from benign to severe, yet the terms commonly used to communicate this condition do not convey the possible nuances of epilepsy, nor do they take on the issue of seizure in its own right.

Epileptologists have moved away from the use of the term "epileptics" toward the phrase people with epilepsy, just like other general terms like "the disabled," "the elderly," and "the homeless" have been replaced with phrases like people with disabilities, older adults, and homeless individuals (1). Clearly, the term epileptic has a pejorative connotation and it was an official recommendation by the IOM that the term epileptic should be discontinued. The committee suggested using more precise and less negative terms, such as seizure medications to replace antiepileptic drugs, epilepsy seizures to replace epileptic seizures, and seizure-like events with a psychological basis rather than psychogenic nonepileptic seizures. The point is that these old terms harm our patients.

The stigma that these names convey is neither unique to epilepsy nor new. Ancient scourges including leprosy, plague, and syphilis to modern maladies like AIDS, psychiatric illnesses, colorectal cancer, to name a few, all share common bonds enshrouded in needless shame. It's as though we are 
naturally conditioned to think in terms of "us" or "them," ignoring the fact that everybody's got something to hide. It's ironic that in this age of instant information misinformation still runs rampant and it all begins with a name.

This study by the Koreans conveys two important points. 1) it is difficult and time-consuming to make changes in nomenclature for a condition that is already well known to so many, and 2 ) it is essential to make an investment in changing the names of a condition in order to relieve the psychosocial consequences of the illness. Just like AIDS gave way to HIV, and cancer gave way to specific subtypes of the individual neoplasms, epilepsy terminology will need to evolve in this manner.

Fundamentally, every physician really has to be careful with his or her words. The best doctors are really great editors. They use the right phrase, right moment, are always honest, while immunizing their patients with the right choice of words.
Seizure disorder sounds a lot better than using the word epileptic or epileptic disorder. We should follow the example of the Koreans and proceed with making our own adjustments to the English language to help our patients.

by Joseph I. Sirven, MD

\section{References}

1. Committee of the Public Health Dimensions of the Epilepsies. Epilepsy Across the Spectrum. National Academies Press: Washington, DC; 2012.

2. Kim HD, Kang HC, Kang HC, Lee SA, Huh K. Lee B. Changing name of Epilepsy in Korea; cerebroelectric disorder: my epilepsy story. Epilepsia 2014;55:384-386.

3. US Centers for Disease Control and Prevention. http://www.cdc.gov/ mentalhealth/about_us/stigma-illness.htm. Accessed 5/1/2014. 